\title{
Development of two-stage alkaline refining of oils obtained from low-grade cotton seeds using caustic soda, sodium silicate and microwave radiation
}

\author{
Azimjon Akhmedov ${ }^{*}$, Eldor Rakhmatov, and Dilfuza Rajabova \\ Karshi engineeringeconomics institute, Karshi, Uzbekistan
}

\begin{abstract}
The article substantiates the improved technology of two-stage alkaline refining of oils obtained from low-grade cotton seeds using caustic soda and sodium silicate. On the basis of the technological scheme, the norms of technological modes have been developed. In the pilot production conditions of Karshiyog-extraction JSC, we tested the developed technology of two-stage alkaline refining of oils obtained from low-grade cotton seeds and ultrahigh-frequency radiation. The developed technology makes it possible to significantly reduce the color, acid, and peroxide numbers and the mass fraction of unsaponifiable substances in the resulting oil. This helps to increase the yield of bleached oil, reduce the consumption of bleaching clay and improve the quality and food safety of the resulting product. As a result, the yield of refined cottonseed oil, obtained from lowgrade cotton seeds, increased by 1.1 times (90\%) (compared to the traditional one (85.1)).
\end{abstract}

\section{Introduction}

Alkaline refining of vegetable oils is considered a chemical process, where, along with the interaction of free fatty acids with alkali, complex soap stocks are formed, which contain soaps, phospholipids, gossypol, chlorophyll and their derivatives, triacylglycerides, free alkali, water, etc. [1]. The chemical reaction taking place inside the water-oil emulsion contributes to its stabilization, sedimentation of soap stock, the release of moisture, etc. [2]. Therefore, along with the use of chemical reagents to neutralize free fatty acids, it has recently been recommended to use physical methods of influencing such emulsions, which include ETE - electromagnetic treatment of an emulsion, microwave radiation (super highfrequency radiation), etc. The role of the latter is manifested in the change in the dipole moment, polarity, and surface tension of electric car components of vegetable oils [3-5]. Their change contributes to the intensification of the processes of coagulation, association, micelle formation, etc. Moreover, according to our research results, the most powerful electrophysical method of influencing water-oil emulsions is considered to be microwave

*Corresponding author: ahmedov80@mail.ru 
radiation, i.e., microwave radiation flowing at $\mathrm{H}=2450 \mathrm{MHz}$ and at a power of $\mathrm{W}=600 \mathrm{~W}$ for up to 5 minutes [6].

Such a short exposure period can significantly reduce energy consumption compared to ETE and other physical methods. Moreover, an important indicator of the quality of refined cottonseed oil is its color, which is measured with a cuvette thickness of $13.5 \mathrm{~cm}$ layer at 35-79.9 yellow on the Lovibond device (Great Britain) [7-9]. According to the standard, to achieve bleached cotton oils with a color of 8 red units, it is necessary to carry out a number of technological processes of its processing (alkaline neutralization, washing, drying, and bleaching). The results of practical observation of these processes and quality indicators of the obtained cotton oils according to the above scheme revealed that for low-grade seeds, it is practically impossible to achieve the color of refined and bleached oil of 8 red units. Therefore, we recommended additionally use a $50 \%$ aqueous solution of nitrilehylphosphonic acid in the process of watering a mixture of oil with alkali to discolor the resulting oil by binding it with gossypol, chlorophyll, and their derivatives [10].

Taking this into account, we have developed an improved technology for two-stage alkaline refining of oils obtained from low-grade cotton seeds using caustic soda and sodium silicate.

\section{Methods}

The article uses modern chemical, physicochemical, spectral, as well as standardized physical and mechanical, technological, and operational test methods [11-13].

\section{Results and Discussion}

In fig. 1 shows an improved technological scheme of two-stage alkaline refining of oils obtained from low-grade cotton seeds using caustic soda and sodium silicate, as well as microwave radiation.

The developed technology of two-stage alkaline refining of oils obtained from lowgrade cotton seeds using caustic soda, sodium silicate, and microwave radiation is carried out as follows: raw cottonseed oil is fed through scales 1 to tank 2 (workshop collection), from where it is pumped 3 through a heat exchanger 4 into a jet reactor-turbulizer 11 .

Simultaneously with the cottonseed oil, a working solution of alkali of the required concentration is supplied to the turbulizer 11 from the tank 8 by the pump 9 through the cooler 10. The concentrated alkali solution $(\mathrm{NaOH})$ is stored in the shop tank 5, equipped with a steam coil. The circulation of the alkali solution, if necessary, is carried out by pump 6 from the tank 5 , the concentrated alkali solution by the pump 6 is fed through filters 7 to the tank 8 , where demineralized water also flows by gravity, which is prepared in a typical demineralization plant.

The resulting mixture (oil, soap flakes, phosphatides, etc.) from the turbulator 11 is transferred under pressure created by the pumps 9 and 12, through microwave radiation 13 and the exposition 16 to the watering device 17 , where the calculated amount of water from collection 19. From the watering device 17, the mixture flows by gravity into a continuous disk separator 20, where the soap stock is separated from the cottonseed oil. Partially neutralized cottonseed oil from the upper part of the separator 20 through the collector enters the intermediate tank 21, which acts as a control sump. From the intermediate tank 21 , through a level stabilizer, partially refined cottonseed oil is continuously pumped out of the turbulator 24 to the second stage of its refining using a sodium silicate solution by a 
pump 22 through a heat exchanger 23 . Simultaneously with partially refined cottonseed oil, a working solution of sodium silicate of the required concentration is fed into the turbulator 24 from the tank 28 by a pump 29 through a heat exchanger 30 . The concentrated sodium silicate solution is stored in a shop tank 25 equipped with a steam coil.

The circulation of the sodium silicate solution, if necessary, is carried out with a pump 26 ; from the tank 25 , the concentrated sodium silicate solution by the pump 26 through the filters 27 falls into the tank 28 , where demineralized water also flows by gravity, which is prepared in a typical demineralization plant.

The resulting mixture (oil, soap flakes, phosphatides, etc.) from the turbulator 24 is transferred under pressure created by the pumps 22 and 29, through microwave radiation 33 and the exposure device 36 into the obturator 38, where the calculated amount of water from the collector is fed into it by the dosing pump 3940 . From the watering device 39, the mixture flows by gravity into a continuous separator (without plates), where the soap stock is separated from the refined cottonseed oil.

Neutralized (refined) cottonseed oil from the upper part of the separator 41 through the collector enters the intermediate tank 54, which acts as a control sump. Refined cottonseed oil is continuously pumped out of the intermediate tank 54 through a level stabilizer for washing by a pump 55 through a heat exchanger 56 .

From the separator 20 using the plates of the separator 20, liquid soap stock (obtained using caustic soda) from the bottom of the apparatus is continuously pumped by a dosing pump 31 into one of the soap stock collectors 43 while maintaining a constant soap stock level in the separator 20 , which is controlled by taking a sample from a test tap located at the top of the bottom and divider 20. If there is a certain amount of oil in the collector 43 of the separator, then it is periodically sucked out of the upper part of the collector by vacuum into the vacuum collector 46 , from where it is pumped into the non-standard oil tank. Vacuum in collector 46 is created by vacuum pump 47. 

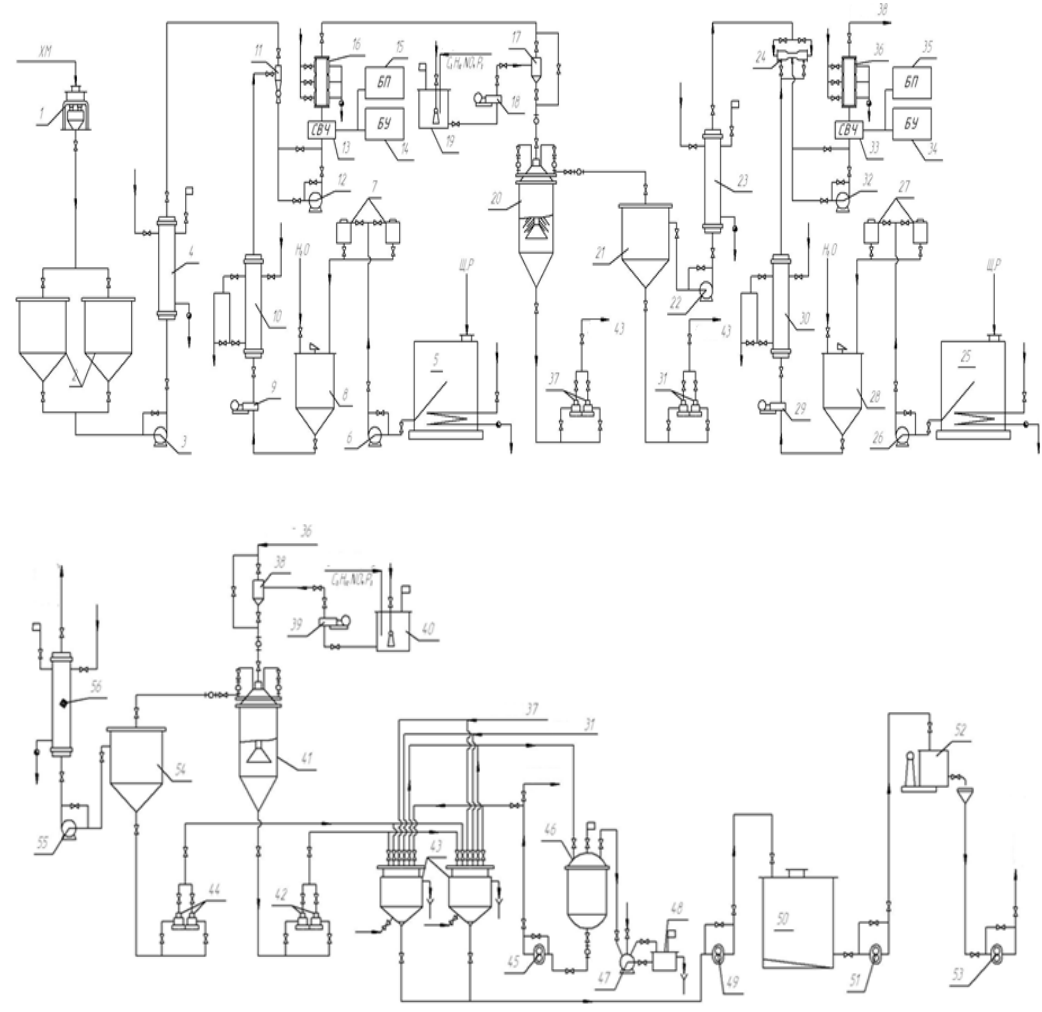

1 are scales; 2 is tank; 3, 6, 12, 22, 26, 32 is pump; 4,23 is heat exchanger; 5 is tank for alkali; 7, 27 filter; 8 is tank for working solution of alkali; 9, 18, 29 is pump dispenser; 10, 30-cooler; 11, 24 is reactor-turbulizer; 13,33 is microwave radiation; 14,34 is control unit; 15,35 is power supply; 16,36 is exposure; 17 is watering device; 19 is tank for water solution; nitrilotris methylenephosphonic acid; 20 is poppet separator; 21 is tank for refined oil; 25 is tank for sodium silicate; 28 is tank for working solution of sodium silicate; 31,37 is piston pump. 38 is water supply; 39 is pump dispenser; 40 is tank for water solution. nitrilotris methylenephosphonic acid; 41 is separator; 42,44 is piston pump; 43, 50 is tank for soap stock; 5; 49, 51, 53-pump; 46 is vacuum collector; 47 is vacuum pump; 48 is drip catcher; 52 is scales for soap stock; 54 is tank for refined oil; 55 is pump; 56 is heat exchanger.

Fig.1. Improved technological scheme of two-stage alkaline refining of oils obtained from low-grade cotton seeds using caustic soda, sodium silicate and UHFR

Soap stock from collectors 43 is pumped out by pump 45 into shop tanks 50, from where, as necessary, pumps 51 and 53 are fed through scales 52 for further processing (for saponification, decomposition, etc.). The soap stock obtained using sodium silicate from the bottom of the separator 41 is continuously pumped out by a dosing pump 42 into one of the collectors of soap stock 43 while maintaining a constant level of soap stock in the separator 41 , which is controlled by taking a sample from a test tap located in the upper part of the bottom of the separator 4 .

On the basis of this technological scheme, the norms of technological modes of twostage refining of oil obtained from low-grade cotton seeds using caustic soda, sodium silicate, and microwave radiation have been developed. 
Table 1 shows the norms of technological parameters of the line of two-stage refining of oil obtained from low-grade cotton seeds using caustic soda, sodium silicate, and microwave radiation.

Refined oil obtained from low-grade cotton seeds, in most cases, has an increased color, which is not allowed by the requirements of the standard [14-15]. Therefore, after alkaline refining, cottonseed oil undergoes traditional bleaching using activated clays, coal, and their compositions [16-17]. After such purification, refined cottonseed oil is sent for deodorization to depersonalize smell and taste, as well as to remove carcinogenic fatty acids, etc.

Table 1. Norms of the technical regime for two-stage refining of oil obtained from low-grade cottonseeds using caustic soda, sodium silicate and UHFR

\begin{tabular}{|c|c|c|}
\hline \multicolumn{2}{|r|}{ Stage name and technological parameters } & \multirow[t]{2}{*}{ The values } \\
\hline I & The first stage of refining cotton seed oil with caustic soda & \\
\hline- & Initial cotton seed oil temperature, ${ }^{\circ} \mathrm{C}$ & Not higher than 30 \\
\hline- & Oil temperature in front of the turbulator, ${ }^{\circ} \mathrm{C}$ & $20-22$ \\
\hline- & $\begin{array}{l}\text { The temperature of the aqueous solution of caustic soda in front } \\
\text { of the turbulator, }{ }^{\circ} \mathrm{C}\end{array}$ & $20-22$ \\
\hline- & Pressure in front of the mixer, $\mathrm{kgf} / \mathrm{cm} 2$ & $3,0-4,0$ \\
\hline- & UHFR, MHz & 2450 \\
\hline- & UHFRpower, W & 600 \\
\hline- & UHFR processing time, $\min$ & no more than 5.0 \\
\hline \multirow[t]{4}{*}{-} & Temperature in a three-zone exposure, ${ }^{\circ} \mathrm{C}$ : & \\
\hline & - in the first zone & $30-45$ \\
\hline & - in the second zone & $45-55$ \\
\hline & - in the third zone & $55-70$ \\
\hline - & $\begin{array}{l}\text { Consumption of a } 50 \% \text { aqueous solution of nitrilotris } \\
\text { methylenephosphonic acid, } \mathrm{kg} / \mathrm{t} \text { (instead of watered water) }\end{array}$ & Up to 4.0 \\
\hline- & Oil temperature in the disc separator, ${ }^{\circ} \mathrm{C}$ & $45-55$ \\
\hline- & Soap content in oil at the exit from the intermediate tank, $\%$ & No more than 0.5 \\
\hline II & Second stage of cotton seed oil refining with sodium silicate & \\
\hline- & Temperature of cotton seed oil entering the turbulator, ${ }^{\circ} \mathrm{C}$ & $20-22$ \\
\hline- & $\begin{array}{l}\text { The temperature of an aqueous solution of sodium silicate in } \\
\text { front of the turbulator, }{ }^{\circ} \mathrm{C}\end{array}$ & $20-22$ \\
\hline- & Pressure in front of the mixer, $\mathrm{kgf} / \mathrm{cm} 2$ & $3,0-4,0$ \\
\hline \multirow[t]{3}{*}{-} & UHFR, $\mathrm{MHz}$ & 2450 \\
\hline & UHFRpower, W & 600 \\
\hline & UHFR processing time, $\min$ & No more than 5.0 \\
\hline \multirow[t]{4}{*}{-} & Temperature in a three-zone exposure, ${ }^{\circ} \mathrm{C}$ : & \\
\hline & - in the first zone & $30-45$ \\
\hline & - in the second zone & $45-55$ \\
\hline & - in thethir dzone & $55-70$ \\
\hline- & $\begin{array}{l}\text { Consumption of a } 50 \% \text { aqueous solution of nitrilotris } \\
\text { methylenephosphonic acid, } \mathrm{kg} / \mathrm{t} \text { (instead of watered water) }\end{array}$ & upto 2.0 \\
\hline- & Temperature in the separator, ${ }^{\circ} \mathrm{C}$ & $45-55$ \\
\hline \multirow[t]{2}{*}{ - } & Soap content in oil at the exit from the intermediate tank, $\%$ & No more than 0.5 \\
\hline & Collection of soap stocks & \\
\hline- & Control of neutral fat in soap stock, $\%$ & No more than 30 \\
\hline- & Soap stock temperature, ${ }^{\circ} \mathrm{C}$ & no more than 50 \\
\hline- & Vacuum on the line for pumping oil from soap stock, $\mathrm{mm} \mathrm{Hg}$ & $10-16$ \\
\hline- & Soap stock pressure, $\mathrm{kgf} / \mathrm{cm} 2$ & No more than 5.0 \\
\hline
\end{tabular}


Using high-performance liquid chromatography (HPLC), samples of crude and preclarified urea-modified clay adsorbents (URMCA) oils obtained from low-grade oils, and their mixtures with non-standard seeds were studied [18-19]. The results are shown in Fig. 1.

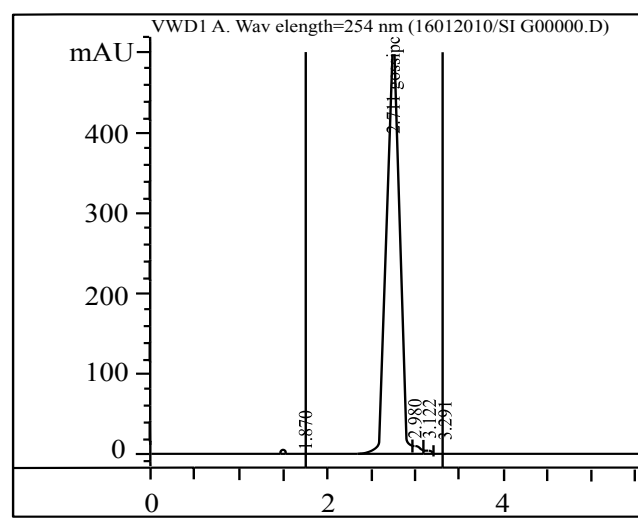

a)

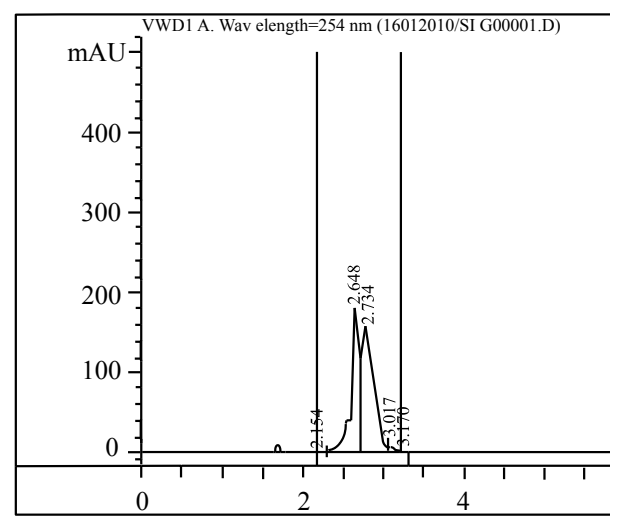

b)

Fig.2. Chromatogram of the analysis of the content of gossypol in raw (a) and pre-clarified MCHA (b) oil obtained from low-grade cotton seeds

Figure 2 it can be seen that due to preliminary clarification of crude oil obtained from low-grade cotton seeds using URMCA-4 in an amount of $5 \%$ of the oil mass, the content of gossypol in it decreases by about $20-25 \%$, which has a beneficial effect on the subsequent processes of refining and bleaching of oils.

Consequently, the use of preliminary clarification of crude oils obtained from low-grade cotton seeds with the use of MCHA contributes to an increase in the efficiency of subsequent processes of refining and bleaching of the resulting oils [20-21].

Transferring a one-stage cottonseed oil refining process to a two-stage process reduces the loss of valuable oil, increases its yield after this treatment, and ensures that the quality indicators of the resulting product comply with the requirements of the standard [22-25].

Table 2 presents data on the conditions for the refining of cotton oils and on the indicators of the products obtained.

From table. 2, it can be seen that after two-stage alkaline refining of cottonseed oil with the proposed changes, its yield increases by $3-4 \%$, which significantly reduces the loss of oil in soap stock and its cost.

The results of analyzes of refined oils obtained from low-grade cotton seeds are presented in Table 3. 
Table 2. Condition sand indicators of cottonseed oil refining

\begin{tabular}{|c|c|c|c|c|c|c|c|}
\hline \multicolumn{4}{|c|}{ Refining conditions } & \multicolumn{4}{|c|}{ Oil indicators } \\
\hline Number & $\begin{array}{l}\text { concentratio } \\
\mathrm{n} \text { of alkaline } \\
\text { reagent } \mathrm{g} / \mathrm{l}\end{array}$ & $\begin{array}{c}\text { exces } \\
\text { salkali,\% }\end{array}$ & $\mathrm{T}, 0 \mathrm{C}$ & $\begin{array}{c}\text { Acid } \\
\text { number mg } \\
\mathrm{KOH} / \mathrm{g}\end{array}$ & $\begin{array}{c}\text { Chromatic } \\
\text { ity, red } \\
\text { units at } 35 \\
\text { yellow. }\end{array}$ & $\begin{array}{c}\text { Soap and } \\
\text { alkali,\% }\end{array}$ & $\begin{array}{c}\text { Yield, } \\
\%\end{array}$ \\
\hline \multicolumn{8}{|c|}{ Initialoilindicators: } \\
\hline 1 & - & - & - & 2.6 & 54.2 & - & - \\
\hline \multicolumn{8}{|c|}{ One-step alkaline cottonseed oil refining } \\
\hline 2 & 250 & 250 & $40-50$ & 0.3 & $12-14$ & 0.01 & 85.1 \\
\hline \multicolumn{8}{|c|}{ Two-stage alkaline cottonseed oil refining (first stage, $\mathrm{NaOH}$ ) } \\
\hline 3 & 125 & 150 & $50-60$ & $0,6-0,9$ & $26-28$ & $0,08-0,10$ & 92,6 \\
\hline \multicolumn{8}{|c|}{ Two-stage alkaline cottonseed oil refining (second stage, $\mathrm{Na}_{2} \mathrm{SiO}_{3}$ ) } \\
\hline 4 & 75 & 100 & $50-60$ & $0.3-0.5$ & $16-20$ & $0.02-0.4$ & $89-90$ \\
\hline
\end{tabular}

Table 3. Results of a pilot production test of the developed technology of two-stage alkaline refining of dark press oil obtained from low-grade cotton seeds using an aqueous solution of caustic soda at the first stage and sodium silicate at the second stage.

\begin{tabular}{|c|c|c|c|c|c|}
\hline \multirow{2}{*}{ Oil refining technology name } & \multicolumn{2}{|c|}{$\begin{array}{c}\text { Lovibond color of oil in } \\
13.5 \mathrm{~cm} \text { layer at 35 } \\
\text { yellow units in: }\end{array}$} & $\begin{array}{c}\text { Acid } \\
\text { number of } \\
\text { oil, } \mathrm{mg} \\
\mathrm{KOH} / \mathrm{g}\end{array}$ & $\begin{array}{c}\text { Peroxide } \\
\text { number of } \\
\text { oil, mmol } \\
\mathrm{O}_{2} / \mathrm{kg}\end{array}$ & $\begin{array}{c}\text { Mass } \\
\text { fraction of } \\
\text { unsaponifiab } \\
\text { lesubstances, } \\
\%\end{array}$ \\
\cline { 2 - 5 } $\begin{array}{c}\text { Traditional emulsion refining } \\
\text { of cottonseed oil (control) }\end{array}$ & 14.5 & 1.3 & 0.4 & 9.2 & 0.9 \\
\hline $\begin{array}{c}\text { Two-stage refining of } \\
\text { cottonseed oil using an } \\
\text { aqueous solution of caustic } \\
\text { soda at the first stage and } \\
\text { sodium silicate at the second } \\
\text { stage }\end{array}$ & 11.5 & 0.5 & 0.3 & 8.7 & 0.6 \\
\hline
\end{tabular}

\section{Conclusions}

1. An improved technological scheme of two-stage alkaline refining of oils obtained from low-grade cotton seeds using caustic soda and sodium silicate, as well as microwave radiation, has been developed.

2. Considering the above, in the pilot production conditions of JSC "Karshi oilextraction," we tested the developed technology of two-stage alkaline refining of oils obtained from low-grade cotton seeds using caustic soda, sodium silicate, and UHFR.

3. That the developed technology of two-stage alkaline refining of dark press oil obtained from low-grade cotton seeds using an aqueous solution of caustic soda at the first stage.

4. On the second - sodium silicate can significantly reduce color, acid, and peroxide numbers and the mass fraction of unsaponifiable substances in the resulting oil. This helps to increase the yield of bleached oil, reduce the consumption of bleaching clay and improve the quality and food safety of the resulting product. 
5. Due to preliminary clarification of crude oil obtained from low-grade cotton seeds using URMCA-4 in an amount of 5\% by weight of oil, the content of gossypol in it is reduced by about $20-25 \%$, which favorably affects the subsequent processes of refining and bleaching of oils.

6. After two-stage alkaline refining of cottonseed oil with the proposed changes, its yield increases by $3-4 \%$, which significantly reduces the loss of oil in soap stock and its cost.

\section{References}

1. Technology for processing fats. Edited by prof. Arutyunyan N.S., -M .: Agropromizdat, O'zDSt 2797-2013. Soapstock. Technical conditions. - T.p 31 p. (2013),

2. Yulchiev A.B. The technology of obtaining high-bossypole cottonseed oil using microwave processing. PhD diss. - T., p 120. (2017).

3. Bykova S.F., Klyuchkin V.V., Em I.A. Influence of microwave treatment on intracellular changes in the kernel of cotton seeds with high consumer qualities. Krasnodar. - pp.19-21. (2003).

4. Abdurakhimov S.A. Scientific and technical basis for the development of technological systems for the production and processing of cottonseed oil. Diss. for the degree of doct. tech. Sciences, Krasnodar. p-355. (1992)

5. Akhmedov A.N. Improvement of technology for obtaining easily refined forepress oil from low-grade cotton seeds. Diss. for the degree of doct. tech. Sciences, Tashkent. $\mathrm{p}$ 228. (2020).

6. Akhmedov A.N., PardaevG.E., Suvanova F.U., Abdurakhimov S.A. Effective technology for processing low-grade cotton seeds, Monograph. -Tashkent, "Navruz", April. p 128.

7. Akhmedov A.N., Abdurakhimov S.A. Technology of obtaining refined bleached forepress oil from low-grade cotton seeds, Food Industry. Moscow, (6). -p. 23-26. (2020)

8. Akhmedov A.N., Abdurakhimov S.A. Improvement of the technology of alkaline refining of press oil obtained from low-grade cotton seeds, Universum: technical science. Moscow, 3 (72).pp .59-62. (2020)

9. Akhmedov A.N. Investigation of indicators of cotton oil obtained by the method of prepressing from low-grade cotton seeds, Universum: technical science. Moscow, 4 (61). pp .23-26. (2019).

10. Abou-Donia S.A., Laches J.M., Abou-Donia M.B. High performance liquid chromatographic analysis of gossypol. High performance liquid chromatography analysis of gossypolum). J. Chromatography., 206 (3), pp 606-610. 1981

11. Karishma R., Lakshmi Sahithya U., Suneetha P., et al. Determination of Total Gossypol and Free Gossypol Content in different varieties of Bt and Non Bt Cotton seed extracts by High- Performance Liquid Chromatography (HPLC), Research journal of biotechnology. 11. (2).pp.70-74. (2016).

12. UzDSt 1200-2015.Vegetable oils. Peroxide value measurement method. -T. p 8. (2015).

13. UzDSt 1199-2014.Vegetable oils. Methods for determining chromaticity. -T. p 10. (2014) 
14. UzDSt 1194-2014. Vegetable oils and natural fatty acids. Methods for determining the content of unsaponifiable substances. -T. p 5. (2014)

15. A.N.Akhmedov, S.A.Abdurakhimov, Yu.Kh. Azimov. Bentonite adsorbents modified with carbamide solution, Universum: technical science. Moscow, 10 (67). pp.59-62. (2019)

16. TC 113-12-86-89. Technical conditions. Ascanite-bentonite activated. - M. p 21. (1989).

17. Akhmedov A.N., Abdurakhimov S.A., DustmurodovaS.Zh. Physicochemical indicators of forepean oil obtained from low-grade cotton seeds, Chemistry and Chemical Technology. -Tashkent, 1.pp.75-78. (2018).

18. Akhmedov A.N., Suvanova F.U., Abdurakhimov S.A. Pre-bleaching of prepress oil obtained from low-grade cotton seeds, Chemistry and Chemical Technology. Tashkent,. (4). pp.70-73. (2015).

19. Akhmedov A.N., Suvanova F.U., Abdurakhimov S.A., Farmonov Zh.B. Technology of preliminary clarification of raw oils obtained from low-grade cotton seeds, Uzbek chemical journal. -Tashkent (5). pp.63-66. (2015).

20. Akhmedov A.N., Suvanova F.U., Sagdullaeva D.S., Abdurakhimov S.A. Changes in the structure of kernels, mint and pulp obtained from high and low-grade cotton seeds, Chemistry and Chemical Technology. -Tashkent, (1) pp.68-71. (2019).

21. Akhmedov A.N., Abdurakhimov S. A. Investigation of the process of grinding rushanka from kernels of cotton seeds of various varieties, Chemistry and chemical technology. -Tashkent,. (3). pp.69-71. (2018).

22. Akhmedov A.N., Abdurakhimov S.A. Investigation of the process of rolling of cotton seed, and chemical technology. -Tashkent, (2). pp.72-75.(2018).

23. Akhmedov A.N., Suvanova F.U., Abdurakhimov S.A., Ikromov O.A. Investigation of the process of refining oils obtained from low-grade cotton seeds, Chemistry and Chemical Technology. -Tashkent,. (3). pp.69-72. (2014).

24. Akhmedov A.N. Increasing the technology of lightly refined oil obtained from lowgrade cotton seeds, Austrian Journal of Technical and Natural Sciences. - Austria,. (34). pp.11-15. (2019). 